\title{
DESENVOLVIMENTO SUSTENTÁVEL E SUSTENTABILIDADE: EVOLUÇÃO EPISTEMOLÓGICA NA NECESSÁRIA DIFERENCIAÇÃO ENTRE OS CONCEITOS
}

\author{
Maria Cláudia da Silva Antunes de Souza ${ }^{1}$ \\ Charles Alexandre Souza Armada ${ }^{2}$
}

\begin{abstract}
RESUMO: O artigo tem como objeto a análise das categorias Sustentabilidade e Desenvolvimento Sustentável de maneira a identificar suas contradições e aproximações. O objetivo da pesquisa é analisar as diferenciações entre as duas categorias a partir da evolução conceitual e as possibilidades de consolidação da Sustentabilidade. A pesquisa divide-se em três momentos: no primeiro, trata das noções gerais do avanço conceitual da categoria Desenvolvimento Sustentável e as críticas doutrinárias. O segundo aborda a Sustentabilidade e suas dimensões. Finaliza, com possibilidades de consolidação da Sustentabilidade a partir de um efetivo Desenvolvimento Sustentável planetário. Quanto à metodologia, foi utilizada a base lógica indutiva.
\end{abstract}

Palavras-chave: Desenvolvimento Sustentável. Sustentabilidade. Meio Ambiente. Ser humano. Evolução.

\section{SUSTAINABLE DEVELOPMENT AND SUSTAINABILITY: EPISTEMOLOGICAL EVOLUTION IN THE NECESSARY DIFFERENTIATION BETWEEN CONCEPTS}

\begin{abstract}
The article aims to analyze the categories Sustainability and Sustainable Development categories in order to identify their contradictions and approximations. The objective of the research is to analyze the differences between the two categories from the conceptual evolution and from the possibilities of consolidation of Sustainability. The research is divided in three moments: in the first, it deals with the general notions of the conceptual advance of the Sustainable Development category and its doctrinal critiques. The second deals with Sustainability and its dimensions. It ends, with possibilities for the consolidation of
\end{abstract}

\footnotetext{
${ }^{1}$ Doutora e Mestre em Derecho Ambiental y de la Sostenibilidad pela Universidade de Alicante - Espanha. Mestre em Ciência Jurídica pela Universidade do Vale do Itajaí - UNIVALI. Professora no Programa de Pós-Graduação Stricto Sensu em Ciência Jurídica, nos cursos de Doutorado e Mestrado em Ciência Jurídica, e na Graduação no Curso de Direito da Universidade do Vale do Itajaí - UNIVALI. Coordenadora do Grupo de Pesquisa "Estado, Direito Ambiental, Transnacionalidade e Sustentabilidade" cadastrado no CNPq/EDATS/UNIVALI. Coordenadora do Projeto de pesquisa aprovado no CNPq intitulado: "Possibilidades e Limites da Avaliação Ambiental Estratégica no Brasil e Impacto na Gestão Ambiental Portuária". E-mail: mclaudia@univali.br

${ }^{2}$ Doutor e Mestre em Derecho Ambiental y de la Sostenibilidad pela Universidade de Alicante - Espanha. Doutor e Mestre em Ciência Jurídica pela Universidade do Vale do Itajaí - UNIVALI. Professor na Graduação dos cursos de Direito, Relações Internacionais e Logística da Universidade do Vale do Itajaí - UNIVALI. Professor na PósGraduação Lato Sensu do Curso de Relações Internacionais. Coordenador do Grupo de Estudos em Direito Internacional Ambiental e Governança Global do Centro de Ciências Sociais e Jurídicas - CEJURPS da Universidade do Vale do Itajaí - UNIVALI.
} 
Sustainability from an effective Planetary Sustainable Development. Regarding the methodology, the inductive logic base was used.

Keywords: Sustainable Development. Sustainability. Environment. Human being. Evolution.

\section{INTRODUÇÃO}

O desenvolvimento do ser humano no planeta, evidenciado pelos avanços tecnológicos, intensificou-se ao longo dos últimos 200 anos. Nesse período, o homem buscou veemente controlar a natureza. No entendimento de Arnold Toynbee, "o homem é a primeira espécie de ser vivo em nossa biosfera que adquiriu o poder de destruí-la e, ao assim fazer, de liquidar a si mesmo". 3

Principalmente a partir da década de 70, o crescimento desordenado das cidades e o aumento no ritmo de crescimento populacional alterou de forma significativa a delicada constituição da biosfera, termo utilizado por Arnold Toynbee para designar a "película de terra firme, água e ar que envolve o globo do planeta Terra". ${ }^{4}$

No início da década de 80, os problemas intensificaram-se e, os danos ambientais tornaram-se recorrentes. Edgar Morin apresenta os principais sinais de alerta que surgiram nesse período:

a) grandes catástrofes locais com amplas consequências (acidentes nucleares nas usinas de Chernobyl e Three Mile Island, poluição do ar em Atenas e na Cidade do México, etc);

b) problemas mais gerais nos países industrializados (urbanização maciça, contaminação das águas, envenenamento dos solos por pesticidas e fertilizantes);

c) problemas mais gerais nos países não-industrializados (desertificação, desmatamento, etc);

d) problemas globais relativos ao planeta como um todo (efeito estufa, decomposição da camada de ozônio, etc). ${ }^{5}$

Edgar Morin e Arnold Toynbee expõem uma dualidade ou contraposição de forças em processo. De um lado, a constatação da fragilidade do planeta aliada à questão da limitação de seus recursos; e, de outro lado, a percepção de que o homem possui a capacidade de destruir o planeta pela ação indiscriminada na exploração desses recursos. Apesar da gravidade na

\footnotetext{
${ }^{3}$ TOYNBEE, Arnold. A humanidade e a mãe-terra: uma história narrativa do mundo. Rio de janeiro: Guanabara, 1987. p. 36.

${ }^{4}$ TOYNBEE, Arnold. A humanidade e a mãe-terra: uma história narrativa do mundo. p. 22.

${ }^{5}$ MORIN, Edgar; KERN, Anne Brigitte. Terra-Pátria. Porto Alegre: Sulina, 1995. p. 73.
} 
constatação, a escalada da degradação ambiental continuou ao longo do século XX e primeiras décadas do século XXI.

Um novo paradigma impõe-se à sociedade pós-moderna. A crise ambiental é também uma crise da civilização, do esgotamento de um modo de vida baseado no consumo. A insustentabilidade do atual processo de desenvolvimento passa, também, pelas dificuldades conceituais associadas às categorias Sustentabilidade e Desenvolvimento Sustentável, o que justifica a presente pesquisa.

Assim, este artigo tem como objeto a análise das categorias Sustentabilidade e Desenvolvimento Sustentável de maneira a identificar suas contradições e aproximações. Sendo assim, o objetivo da pesquisa é analisar as diferenciações entre as duas categorias a partir da evolução conceitual de ambas e as possibilidades de consolidação da Sustentabilidade. Destaca como problemas de pesquisa: a Sustentabilidade representa um novo repensar dos valores humanos e das visões políticas? O conceito de Sustentabilidade deverá permear concepções, planos, políticas e agendas de ação de uma nova ordem mundial? O Desenvolvimento Sustentável é o reconhecimento de que os objetivos econômicos e ambientais são indissociáveis?

O presente estudo está dividido em três momentos: no primeiro, trata das noções gerais do avanço conceitual da categoria Desenvolvimento Sustentável e suas críticas doutrinárias. O segundo faz considerações sobre a Sustentabilidade e suas dimensões. O terceiro compreende os aspectos gerais sobre as possibilidades de consolidação do conceito de Sustentabilidade a partir de um efetivo Desenvolvimento Sustentável planetário.

Quanto à metodologia, foi utilizada a base lógica indutiva, por meio da pesquisa bibliográfica a ser utilizada no desenvolvimento da pesquisa, o método cartesiano, quanto à coleta de dados, e, no relatório final, o método indutivo ${ }^{6}$ com as técnicas do referente, da categoria, dos conceitos operacionais, da pesquisa bibliográfica e do fichamento.

Por fim, espera-se com este estudo contribuir para a reflexão acerca dos temas Sustentabilidade e Desenvolvimento Sustentável, com enfoque especial na aplicabilidade

\footnotetext{
6 “[...] pesquisar e identificar as partes de um fenômeno e colecioná-las de modo a ter uma percepção ou conclusão geral [...]". PASOLD, Cesar Luiz. Metodologia da pesquisa jurídica: teoria e prática. $13^{\mathrm{a}}$ ed. Florianópolis: Conceito Editorial. 2015.p. 86.
} 
destes institutos como ferramentas para a efetivação de uma relação saudável do homem com o meio ambiente.

\section{EVOLUÇÃO CONCEITUAL DO DESENVOLVIMENTO SUSTENTÁVEL}

O grande desafio que se apresenta nestas primeiras décadas do século XXI é, sem dúvida, romper os paradigmas relacionados com o modo de vida consumocentrista que caracteriza a sociedade pós-moderna contemporânea.

Atualmente, o consumo vem em destaque, deixando para segundo plano as preocupações com todos os demais aspectos relacionados com a vida humana incluindo-se, nesse sentido, a preservação do meio ambiente.

O alerta não é recente, já havia sido dado em 1972 com a publicação do estudo intitulado 'Os Limites do Crescimento', também conhecido como Relatório Meadows. Neste estudo, os autores simularam a interação do homem e o meio ambiente levando em consideração o aumento populacional e o esgotamento dos recursos naturais.

Em 1987, novo alerta da comunidade científica é feito através da publicação do estudo intitulado 'Nosso Futuro Comum', também chamado de Relatório Brundtland. Desenvolvido no processo preparatório para a Conferência das Nações Unidas sobre o Meio Ambiente e o Desenvolvimento, a Eco-92, o Relatório Brundtland apresentavam uma lista de ações a serem tomadas pelos Estados e, também definiam metas a serem realizadas em âmbito internacional, tendo como agentes as diversas instituições multilaterais.

A definição para Desenvolvimento Sustentável contida nesse relatório é apresentada da seguinte maneira: "desenvolvimento sustentável é aquele que atende as necessidades do presente sem comprometer as possibilidades de as gerações futuras atenderem suas próprias necessidades". 7

O Relatório conclui alertando que a definição de Desenvolvimento Sustentável contém, dentro dela, dois conceitos-chave: necessidades e limitações. O conceito de necessidades está associado às necessidades essenciais dos pobres do mundo enquanto que a

\footnotetext{
7 UNITED NATIONS. Our Common Future. Disponível em: <http://www.un-documents.net/our-commonfuture.pdf>. Acesso em: 28 jul. 2017. Tradução do autor. Texto original em espanhol: "Sustainable development is development that meets the needs of the present without compromising the ability of future generations to meet their own needs".
} 
ideia de limitações está relacionada ao estado da tecnologia e organização social na capacidade do meio ambiente de atender às necessidades atuais e futuras ${ }^{8}$.

O documento 'Nosso Futuro Comum' apontava para a grande questão da Humanidade. De acordo com Novaes:

Reconhecer que o planeta é finito, não tem recursos infindáveis; por isso, a Humanidade precisa adotar formatos de viver - padrões de produção e consumo - sustentáveis, que não consumam mais recursos do que a biosfera terrestre é capaz de repor; não comprometam o meio ambiente, os muitos biomas do planeta, os seres vivos que neles vivem, as cadeias alimentares e reprodutivas; não degradem os seres humanos; além disso, os padrões de viver não poderiam sacrificar recursos e comprometer os direitos das futuras gerações 9 .

O Relatório Brundtland considerou a possibilidade de alterações nos ecossistemas a partir do crescimento econômico. Em adição, alertava expressamente: "Em geral, os recursos renováveis, como florestas e estoques de peixes, não precisam ser esgotados, desde que a taxa de uso esteja dentro dos limites da regeneração e do crescimento natural". ${ }^{10}$ Contudo, as contradições entre o crescimento econômico e a conservação do meio ambiente não foram claramente explicitadas no Relatório Brundtland, principalmente no que se refere à dimensão política envolvendo "as visões e interesses dos vários grupos sociais, com interesses divergentes a respeito do acesso e uso dos recursos naturais". ${ }^{11}$

É importante assinalar que um ano antes da apresentação do Relatório Brundtland a Organização das Nações Unidas (ONU) reconheceu o desenvolvimento como direito humano através da Resolução 41-128. Esta declaração, no seu artigo 1.1, estabelece que:

O direito ao desenvolvimento é um direito humano inalienável em virtude do qual toda pessoa humana e todos os povos estão habilitados a participar do desenvolvimento econômico, social, cultural e político, a ele contribuir e dele desfrutar, no qual todos os direitos humanos e liberdades fundamentais possam ser plenamente realizados ${ }^{12}$.

${ }^{8}$ UNITED NATIONS. Our Common Future. Disponível em: <http://www.un-documents.net/our-commonfuture.pdf>. Acesso em: 28 jul. 2017.

${ }^{9}$ NOVAES, Washington. Agenda 21: um novo modelo de civilização. In: MELLO, Celso de Albuquerque (Coord.). Anuário: direito e globalização, 1: a soberania. Rio de Janeiro: Renovar, 1999. p. 324.

${ }^{10}$ UNITED NATIONS. Our Common Future. Disponível em: <http://www.un-documents.net/our-commonfuture.pdf>. Acesso em: 28 jul. 2017. Tradução do autor. Texto original em inglês: "In general, renewable resources like forests and fish stocks need not be depleted provided the rate of use is within the limits of regeneration and natural growth".

${ }^{11}$ DIEGUES, Antonio Carlos S. Desenvolvimento sustentável ou sociedades sustentáveis: da crítica dos modelos aos novos paradigmas. São Paulo em Perspectiva. São Paulo, v. 6, n. 1-2, p. 22-29, jan./jun. 1992. p. 28.

12 UNITED NATIONS. Declaration on the Right to Development. Disponível em: <http://www.un.org/documents/ga/res/41/a41r128.htm>. Acesso em: 06 ago. 2017. 
Nota-se que o artigo 1.1 da Resolução da ONU preocupa-se com o direito ao desenvolvimento econômico, mas não trata da questão ambiental. Esse é, portanto, o cenário que antecedeu a publicação do Relatório Brundtland.

Apesar das ressalvas no texto do Relatório, as três décadas que se seguiram à apresentação do documento demonstraram, na prática, a insustentabilidade do desenvolvimento praticado.

Dentre os vários exemplos que podem ser assinalados para corroborar o caráter insustentável do desenvolvimento a partir do Relatório Brundtland, o comportamento das emissões de gases de efeito estufa no período talvez seja o mais emblemático. Embora os Estados tenham se mobilizado no sentido de tentar frear o comportamento crescente das emissões, elas continuaram em ritmo crescente mesmo depois da entrada em vigor do Protocolo de Quioto.

Segundo Pierri, o Relatório Brundtland inverte a formulação clássica do problema entre desenvolvimento e preservação ambiental: se distancia do ecocentrismo que via o desenvolvimento como causa da degradação ambiental e adota uma clara ótica antropocentrista dizendo que a preocupação está em evitar-se que esta degradação limite o desenvolvimento ${ }^{13}$.

Em 1992, durante a Conferência das Nações Unidas sobre o Meio Ambiente e o Desenvolvimento, a ECO-92, foram elaborados alguns documentos importantes que reforçavam a necessidade de um desenvolvimento mais sustentável para o planeta. Dentre eles, destacam-se a Declaração do Rio sobre Meio Ambiente e Desenvolvimento e a Agenda 21. O primeiro é composto por 27 princípios e expõe que "busca estabelecer um novo modelo de desenvolvimento, fundado na utilização sustentável dos recursos ambientais, no respeito à capacidade do Planeta [...] e na valorização da qualidade ambiental como requisito imprescindível à qualidade de vida [...]". ${ }^{14}$ Juntamente com o segundo documento, a Agenda 21, o termo Desenvolvimento Sustentável foi definitivamente popularizado pela ampla cobertura da mídia à Conferência. No entanto, naquela época, o uso indiscriminado deste termo era criticado, sobretudo nos discursos governamentais e nos projetos de desenvolvimento.

${ }^{13}$ PIERRI, Naína. Historia del concepto de desarrollo sustentable. In: FOLADORI, Guilhermo; PIERRI, Naína (Coords). ¿Sustentabilidad? Desacuerdos sobre el desarrollo sustentable. México, H. Cámara de Diputados, Universidad Autónoma de Zacatecas y Porrúa. p. 60. Tradução do autor. Texto original em espanhol: "se distancia del ecocentrismo,que veía el desarrollo como causa del deterioro ambiental, y adopta una clara óptica antropocentrista diciendo que hay que preocuparse por evitar que ese deterioro limite el desarrollo".

${ }^{14}$ MILARÉ, Édis. Direito do Ambiente - doutrina - jurisprudência - glossário. 4. ed. rev., atual. E ampl. São Paulo: Editora Revista dos Tribunais, 2005. p. 1021/1022. 
Temia-se que pudesse se tornar mais um dos modismos incorporados pelas elites, sobretudo do terceiro mundo, uma "maquiagem de velhos discursos com uma coloração "verde", 15.

A esse respeito, Elkington assinala que:

A pauta da sustentabilidade, há tempos conhecida como uma tentativa de harmonizar o pilar financeiro tradicional com o pensamento emergente sobre o pilar ambiental, está agora se revelando muito mais complicada do que aquilo que alguns executivos entusiastas haviam imaginado no início ${ }^{16}$.

A sustentabilidade é a capacidade de um sistema humano, natural ou misto para resistir ou se adaptar à mudança endógena ou exógena por tempo indeterminado ${ }^{17}$, representada como uma meta ou um ponto final. Portanto, para alcançar a sustentabilidade requer-se o desenvolvimento sustentável. O conceito de Desenvolvimento Sustentável permanece impugnado devido as diferentes posições tomadas em relação ao que pode ser considerado justo. É tão amplo e genericamente aplicável que sua imprecisão o torna inoperante e aberto ao conflito de interpretações. Por sua vez, quase todas as definições publicadas sobre o conceito de Desenvolvimento Sustentável têm como base princípios da sustentabilidade, por exemplo, a perspectiva de longo prazo, importância fundamental das condições locais, compreensão da evolução não linear dos sistemas ambientais e humanos.

Em 1997, Elkington sugeriu que a atividade corporativa deveria ser orientada por três dimensões: pela lógica do desenvolvimento (dimensão econômica), ser socialmente justa (dimensão social) e ser ambientalmente correta (dimensão ambiental). Esse modelo ficou conhecido como Triple Bottom Line (Profits, People, Planet). Seu modelo propunha que as organizações visassem, além do desempenho econômico, também as dimensões ambientais e sociais ${ }^{18}$. Sendo recepcionado nos documentos oficiais da Conferência das Nações Unidas em Joanesburgo em 2002.

${ }^{15}$ DIEGUES, Antonio Carlos S. Desenvolvimento sustentável ou sociedades sustentáveis: da crítica dos modelos aos novos paradigmas. São Paulo em Perspectiva. São Paulo, v. 6, n. 1-2, p. 22-29, jan./jun. 1992. p. 29.

${ }^{16}$ ELKINGTON, John. Canibais com garfo e faca. São Paulo: M. Books do Brasil Editora Ltda, 2012. p. 33.

${ }^{17}$ DOVERS, S.R.; HANDMER, J.W. Uncertainty, sustainability and change. Global Environmental Change, v.2, n.4, p.262-276, 1992.

${ }^{18}$ VIZEU, Fabio; MENEGHETTI, Francis Kanashiro; SEIFERT, Rene Eugenio. Por uma crítica ao conceito de desenvolvimento sustentável. 3Cad. EBAPE.BR, v. 10, nº 3, artigo 6, Rio de Janeiro, Set. 2012. p. 574. 
Para Bodnar ${ }^{19}$, a partir de 2002 que passa a ser adequado utilizar a expressão "Sustentabilidade" pela consolidação das perspectivas ecológica, social, espacial, econômica; destacando que a importância se dá através do equilíbrio destas dimensões.

$\mathrm{Na}$ agenda da Sustentabilidade, tida para harmonizar o pilar financeiro com o pensamento emergente do pilar ambiental, tornou-se ainda mais complicada do que os executivos haviam imaginado. Atualmente, se pensa nos termos de um dos três pilares, com enfoque na prosperidade econômica, na qualidade ambiental e na justiça social ${ }^{20}$.

Os termos desenvolvimento, desenvolvimento sustentável e sustentabilidade “carregam consigo ambiguidades relacionadas com as tendências de conceitualização do desenvolvimento sustentável"21, inclusive linguísticas, como é o caso dos diferentes significados dos termos anglo-saxônicos sustainable development e, no espanhol, desarrollo sustenible ou sustentable.

Qual é o desenvolvimento que efetivamente precisa ser sustentável? Não se trata unicamente do desenvolvimento econômico, expressão muitas vezes utilizada como sinônimo de crescimento econômico. O Desenvolvimento Sustentável precisa incluir diversas outras esferas da vida humana, além da econômica. Contudo, a falta de detalhamento conceitual abriu espaço para diversas interpretações.

O processo de consolidação do conceito de Desenvolvimento Sustentável recebeu diversas críticas. Freitas, por exemplo, considera a necessidade de aprimoramento do conceito no sentido de deixar nítido que as necessidades atendidas não podem ser aquelas artificiais, fabricadas ou hiperinflacionadas pelo consumismo em cascata. O aprimoramento, de acordo com o autor, se justificaria pelo risco da manutenção, pela nova geração, do mesmo padrão de vida da geração atual, assegurando esta condição para a geração subsequente ${ }^{22}$.

Portanto, um primeiro cuidado na construção do conceito seria evitar um apego excessivo a determinado padrão material de vida. Além disso, de acordo com Freitas, o conceito precisaria ser pronunciadamente includente, política e socialmente ${ }^{23}$.

\footnotetext{
${ }^{19}$ BODNAR, Zenildo; FREITAS, Vladimir Passos de; SILVA, Kaira Cristina. A epistemologia interdisciplinar da sustentabilidade: por uma ecologia integral para a sustentação da casa comum. Revista Brasileira de Direito, 12(2): 59-70, jul.-dez. 2016.

${ }^{20}$ ELKINGTON, John. Canibais com garfo e faca. p. 108.

${ }^{21}$ FREITAS, M. A década de educação para o desenvolvimento sustentável - do que não deve ser ao que pode ser. In: Congresso Ibero-Americano de Educação Ambiental, 5, 2007, Joinville. Anais... Joinville: Associação Projeto Roda Viva, 2007. p. 131.

${ }^{22}$ FREITAS, Juarez. Sustentabilidade: direito ao futuro. 2. ed. Belo Horizonte: Fórum, 2012. p. 47.

${ }^{23}$ FREITAS, Juarez. Sustentabilidade: direito ao futuro. p. 47.
} 
Boff considera que a utilização política da expressão Desenvolvimento Sustentável representa uma armadilha do sistema imperante: "assume os termos da ecologia (sustentabilidade) para esvaziá-los e assume o ideal da economia (crescimento/desenvolvimento), mascarando, porém, a pobreza que ele mesmo produz" ${ }^{24}$.

No mesmo sentido, Veiga considera que os três pilares convencionados tornou possível considerar o meio ambiente 'apenas' a terça parte do desenvolvimento sustentável, "em vez de reforçar o entendimento do meio ambiente como base e condição material de qualquer possiblidade de desenvolvimento humano [...]". ${ }^{25}$

Lima condena sua natureza polissêmica, permitindo interpretações relacionadas com um significado avançado de desenvolvimento, associado à justiça social e preservação ecológica, mas, ao mesmo tempo, também relacionadas com uma leitura conservadora que a aproxima do conceito de crescimento econômico. ${ }^{26}$

Boff e Lima convergem a respeito da significação política do termo Desenvolvimento Sustentável que determina uma alternativa para desviar a atenção de sua limitação conceitual e dos reais problemas ambientais globais.

O conceito de Desenvolvimento Sustentável fundamenta-se no mito das necessidades, segundo Vizeu, e "corrobora a perspectiva desenvolvimentista do capital que entende o ambiente como 'meio' ou repositório de recursos a serem utilizados para satisfação das necessidades humanas". Além disso, "entende necessidades baseadas de uma perspectiva ocidental globalizante que ignora as inúmeras diferenças culturais entre as nações" 27.

Em que pese, o atual modelo de sociedade está baseado no 'desenvolvimento sustentável' da economia e, efetivamente, não ultrapassou o sentido de desenvolvimento econômico; e este não está suportando a pressão exercida pela crise ambiental de âmbito global. Urge, portanto, considerar a Sustentabilidade como paradigma emergente e necessário.

${ }^{24}$ BOFF, Leonardo. Sustentabilidade: o que é, o que não é. Petrópolis, RJ: Vozes, 2015. p. 46.

${ }^{25}$ VEIGA, José Eli da. A desgovernança mundial da sustentabilidade. p. 110.

${ }^{26}$ LIMA, A. G. O debate da sustentabilidade na sociedade insustentável. 1997. Disponível em: <http://www.ufmt.br/gpea/pub/GuLima_sustentabilidade>. Acesso em: 11 abr. 2010.

${ }^{27}$ VIZEU, Fabio; MENEGHETTI, Francis Kanashiro; SEIFERT, Rene Eugenio. Por uma crítica ao conceito de desenvolvimento sustentável. 3Cad. EBAPE.BR, v. 10, nº 3, artigo 6, Rio de Janeiro, Set. 2012. p. 580. 


\section{A SUSTENTABILIDADE MULTIDIMENSIONAL COMO PARADIGMA EMERGENTE E NECESSÁRIO}

Os termos Sustentabilidade e Desenvolvimento Sustentável não devem ser utilizados como sinônimos, por terem significados distintos. Neste momento da pesquisa, passamos a analisar a conceituação de Sustentabilidade e suas dimensões.

Em documentos oficiais, o conceito de Sustentabilidade com um olhar multidimensional surgiu em 2002, na Rio+10, realizada em Johannesburgo, quando restaram reunidas, além da dimensão global, as perspectivas ecológica, social e econômica como qualificadoras de qualquer projeto de desenvolvimento, bem como a certeza de que sem justiça social não é possível alcançar um meio ambiente sadio e equilibrado na sua perspectiva ampla, para as presentes e futuras gerações.

Para Bodnar,

É a partir de 2002 que passa a ser adequado utilizar a expressão 'sustentabilidade', ao invés de desenvolvimento com o qualificativo 'sustentável'. Isso porque, a partir deste ano, consolida-se a ideia de que nenhum dos elementos (ecológico, social, espacial e econômico) deve ser hierarquicamente superior ou compreendido como variável de segunda categoria ${ }^{28}$.

Carvalho, destaque que há uma série de problemas conceituais relacionados com a categoria Sustentabilidade:

O conceito de sustentabilidade apresenta uma alta polissemia, englobando uma grande diversidade de sentidos, podendo ser pensado mais como um conceito em disputa do que uma categoria descritiva e estável no campo de interlocução ambiental. Um dos fatores que contribuem para que a ideia de sustentabilidade mantenha esta alta polissemia é, além da disputa de interesses e projetos políticos que ela abarca, certa indiferenciação entre os diferentes contextos discursivos, sociais e epistemológicos onde ela é aplicada ${ }^{29}$.

Além dos problemas relacionados com sua característica polissêmica, Sustentabilidade é, muitas vezes, confundido com o Desenvolvimento Sustentável. No entanto, para o presente estudo será apresentado os pontos que o tornam distintos.

A Sustentabilidade representa uma mudança fundamental de paradigma, repensando os valores humanos, as visões políticas e as 'regras do jogo' sociais por meio da: eficiência econômica voltada à igualdade social, dos direitos individuais para obrigações

${ }^{28}$ BODNAR, Zenildo; FREITAS, Vladimir Passos de; SILVA, Kaira Cristina. A epistemologia interdisciplinar da sustentabilidade: por uma ecologia integral para a sustentação da casa comum. Revista Brasileira de Direito, 12(2): 59-70, jul.-dez. 2016.

${ }^{29}$ CARVALHO, Isabel Cristina de Moura. Educação para sociedades sustentáveis e ambientalmente justas. REMEA Revista Eletrônica do Mestrado em Educação Ambiental. v. especial. Mar 2008. Rio Grande/RS. p. 46-55. Disponível em: <http://www.seer.furg.br/remea/article/view/3387/2033>. Acesso em: 02 ago. 2017. 
coletivas, do individualismo para comunidade, da quantidade para a qualidade, da separação para a interdependência, da exclusão para a igualdade de oportunidade, do homem para a mulher, do luxo para a necessidade, da repressão para a liberdade, do hoje para o amanhã e do crescimento que beneficia poucos para um desenvolvimento humano que beneficie a todos ${ }^{30}$.

A transformação de valores e visões políticas exige uma grande mudança de mentalidade e cultura, "a fim de que a economia deixe de ser o principal pilar sobre o qual se apoiam as decisões e passe a ser apenas um fator, dentre tantos outros de suma importância, a ser considerado em cada escolha" ${ }^{31}$.

Freitas entende que a Sustentabilidade é pluridimensional e engloba, sem hierarquia rígida e sem caráter exaustivo, a dimensão social, ética, ambiental, econômica e jurídicopolítica $^{32}$.

Para o autor, a dimensão social abriga os direitos fundamentais sociais e reclama o incremento da equidade (intra e intergeracional), condições propícias ao florescimento virtuoso das potencialidades humanas e "o engajamento na causa do desenvolvimento que perdura e faz a sociedade mais apta a sobreviver, em longo prazo, com dignidade e respeito à dignidade dos demais seres vivos" 33 .

Com relação a dimensão ética, Freitas apresenta que a ética da Sustentabilidade reconhece a ligação de todos os seres, o impacto retroalimentador das ações e omissões, a exigência de universalização concreta e o engajamento que admite a dignidade dos seres vivos em geral $^{34}$.

A dimensão ambiental da Sustentabilidade, para Freitas, determina a possibilidade de excepcionais oportunidades para o surgimento de uma nova economia que ultrapassa o culto excessivo dos bens posicionais ${ }^{35}$.

Por fim, a dimensão jurídico-política da Sustentabilidade trata da Sustentabilidade como princípio constitucional, imediato e diretamente vinculante. Com relação a esta última dimensão da sustentabilidade, Canotilho afirma que

No seu conjunto, as dimensões jurídico-ambientais e jurídico-ecológicas permitem falar de um Estado de direito ambiental e ecológico. O Estado de Direito, hoje, só é Estado de Direito se for um Estado protector do ambiente e garantidor do direito ao ambiente; mas o Estado ambiental e ecológico só será Estado de Direito se cumprir os deveres de

\footnotetext{
${ }^{30}$ ELKINGTON, John. Canibais com garfo e faca. p. 188.

${ }^{31}$ SOUZA, Maria Cláudia da Silva Antunes de; GARCIA, Rafaela Schmitt. Sustentabilidade e desenvolvimento sustentável: desdobramentos e desafios pós-relatório brundtland. In: Sustentabilidade meio ambiente e sociedade [recurso eletrônico]: reflexões e perspectivas, volume II. SOUZA, Maria Cláudia da Silva Antunes de; ARMADA, Charles Alexandre. Florianópolis, SC: Empório do Direito, 2016. p. 17.

${ }^{32}$ FREITAS, Juarez. Sustentabilidade: direito ao futuro. p. 58-73.

${ }^{33}$ FREITAS, Juarez. Sustentabilidade: direito ao futuro. p. 60.

${ }^{34}$ FREITAS, Juarez. Sustentabilidade: direito ao futuro. p. 58-73.

${ }^{35}$ FREITAS, Juarez. Sustentabilidade: direito ao futuro. p. 58-73.
} 
juridicidade impostos à actuação dos poderes públicos ${ }^{36}$.

No que se refere às dimensões política e jurídica, sua importância pode ser medida no atual contexto de crise econômica global. Tanto no Brasil quanto no exterior é possível encontrar exemplos de decisões privilegiando a economia em detrimento da sustentabilidade ambiental. Há exemplos de decisões políticas governamentais, como a do atual presidente norte-americano de retirar os Estados Unidos do Acordo de Paris, ou seja, a dimensão política atuando em prol da economia.

Para Carvalho, há pelo menos três níveis de aplicação do conceito de Sustentabilidade. De acordo com a autora, o conceito de Sustentabilidade pode tomar a forma de fenômeno empírico, de ideologia e como categoria compreensiva para repensar o mundo ${ }^{37}$.

Aprofundando os estudos relacionados com o conceito de Sustentabilidade, Ferrer apresenta que a Sustentabilidade possui seis requisitos: a) que a sociedade que construímos seja planetária; b) que alcancemos um pacto de sustentabilidade com a Terra; c) a capacidade de alimentar e dar uma vida digna a todos os habitantes, indistintamente; d) recomposição da arquitetura social com o objetivo de extinguir o modelo opressor que tem por base o conforto e o progresso permitindo, portanto, a justiça social; e) que novos modelos de governança (normas e instituições globais) sejam construídos; f) que seja colocada a ciência e a técnica a serviço do objetivo comum ${ }^{38}$.

Com relação ao primeiro requisito, Ferrer sustenta que nosso destino é comum e, dessa forma, não cabe uma Sustentabilidade parcial de algumas comunidades nacionais ou regionais à margem do que ocorre no resto do planeta ${ }^{39}$.

O segundo requisito determina um pacto com a Terra no sentido de não comprometermos as possibilidades de manutenção dos ecossistemas essenciais para nossa subsistência como espécie.

No que se refere ao terceiro requisito, Ferrer apresenta que para alimentar e oferecer uma vida digna a todos os habitantes do planeta será preciso reconsiderar e reformular os modos de produção e distribuição da riqueza.

O quarto requisito da Sustentabilidade exige a recomposição da arquitetura social de modo que contraponha o privilégio de algumas capas sociais e a exclusão sistemática de legiões de desfavorecidos.

${ }^{36}$ CANOTILHO, José Joaquim Gomes. O Princípio da sustentabilidade como Princípio estruturante do Direito Constitucional. Revista de Estudos Politécnicos - Polytechnical Studies Review, 2010, Vol VIII, nº 13, 007-018. p. 13.

${ }^{37}$ CARVALHO, Isabel Cristina de Moura. Educação para sociedades sustentáveis e ambientalmente justas. REMEA Revista Eletrônica do Mestrado em Educação Ambiental. v. especial. Dez 2008. Rio Grande/RS. p. 46-55. Disponível em: <http://www.seer.furg.br/remea/article/view/3387/2033>. Acesso em: 02 mai. 2013.

${ }^{38}$ FERRER, Gabriel Real. La construcción del Derecho Ambiental. Revista Aranzadi de Derecho Ambiental (Pamplona, Espanã), n. 1, 2002, págs. 73-94.

${ }^{39}$ FERRER, Gabriel Real. La construcción del Derecho Ambiental. Revista Aranzadi de Derecho Ambiental (Pamplona, Espanã), n. 1, 2002, págs. 73-94. 
Como quinto requisito para a Sustentabilidade, Ferrer apresenta que os novos modelos de governança assegurem a prevalência do interesse geral sobre o individualismo não solidário de indivíduos, corporações e Estados.

Finalmente, com relação ao sexto requisito, Ferrer postula que os novos conhecimentos devem ajudar a corrigir os erros do passado de uma civilização energéticodependente como, por exemplo, a captação de $\mathrm{CO} 2$.

Bosselmann defende que a Sustentabilidade passe a ser considerada como metaprincípio.

Como os ideais de justiça e direitos humanos, a sustentabilidade pode ser visto como um ideal para a civilização, tanto a nível nacional e internacional. Quando aceito como um princípio jurídico reconhecido, sustentabilidade informa todo o sistema jurídico, e não apenas as leis ambientais ou não apenas a nível nacional ${ }^{40}$.

Ao ser considerada a Sustentabilidade como meta-princípio, esta passa a ordenar e redesenhar toda a relação social, incluso as relações jurídicas, não se restringindo apenas à questão econômica.

Na mesma linha apresentada por Gabriel Ferrer, Marcionila Fernandes apresentam: Nesse sentido, nossa perspectiva considera necessária uma abordagem que contemple os dois movimentos, considerando o ecológico e o social como processos interligados a partir da modernidade, e que, ao mesmo tempo, resulte numa análise crítica da temática do meio ambiente não comprometida com a reprodução da desigualdade entre homens ${ }^{41}$.

As contribuições doutrinárias apresentadas demonstram o caráter multidisciplinar que envolve o conceito de Sustentabilidade e, também em função desse fato, as dificuldades que a evolução conceitual vem enfrentando. Além disso, cabe ressaltar, trata-se de um conceito em construção teórica.

A importância da evolução conceitual da categoria Sustentabilidade se apresenta, primeiramente, pela impossibilidade de sua dissociação do Direito Ambiental. A utilização irresponsável e desenfreada dos recursos naturais não se coaduna com o caráter limitado desses recursos. A ótica capitalista globalizada nega a lógica contida nessa afirmação exigindo o contrapeso do uso sustentável dos recursos naturais.

Outro fator que atesta a importância da categoria Sustentabilidade é sua obrigatória vinculação à categoria Solidariedade. Aceitar o caráter finito dos recursos naturais e, ato de

${ }^{40}$ BOSSELMANN, Klaus. The principle of sustainability: transforming law and governance. Ashgate, Farnham, 2008. p. 4. Tradução do autor. Texto original em ingles: "Like the ideals of justice and human rights, sustainability can be seen as an ideal for civilization both at national and international level. When accepted as a recognized legal principle, sustainability informs the entire legal system, not just environmental laws or not just at the domestic level".

${ }^{41}$ FERNANDES, Marcionila. Desenvolvimento sustentável: antinomias de um conceito. Raízes. v. 21. N.02. juldez/2002. Campina Grande. p. 246-260. Disponível em: 〈http://www.ufcg.edu.br/ raizes/artigos/Artigo_73.pdf〉. Acesso em: 02 ago. 2017. 
consequência, a possibilidade de colocar em perigo a continuação da Humanidade pelo uso indiscriminado desses recursos é, ao mesmo tempo, incluir o outro no processo de proteção. Mais do que isso, é incluir aqueles que ainda não estão aqui, as gerações futuras, aceitando o direito que estas gerações possuem de desfrutar o patrimônio oferecido pela diversidade cultural e ambiental do planeta.

Sachs também trabalha a categoria Solidariedade diretamente vinculada à dimensão ambiental da Sustentabilidade:

Ela é baseada no duplo imperativo ético de solidariedade sincrônica com a geração atual e de solidariedade diacrônica com as gerações futuras. Ela nos compele a trabalhar com escalas múltiplas de tempo e espaço, o que desarruma a caixa de ferramentas do economista convencional. Ela nos impele ainda a buscar soluções triplamente vencedoras, eliminando o crescimento selvagem obtido ao custo de elevadas externalidades negativas, tanto sociais quanto ambientais ${ }^{42}$.

As diferentes contribuições doutrinárias apontam para a Sustentabilidade como um conceito ainda em construção. Segundo Freitas, tratando do conceito de Sustentabilidade “[...] se encontra em processo de construção e legitimação técnica, em sua identificação e contextualização aos processos socioeconômicos das regiões e dos países" ${ }^{43}$.

Na mesma linha, Bodnar entende a complexidade de construção do conceito de Sustentabilidade e que, além disso, sempre será uma obra inacabada:

Isso porque poderá ser melhorada para atender as circunstâncias de cada caso concreto, o contexto em que está sendo aplicado, bem como o conjunto de variáveis direta ou indiretamente envolvidas. Afinal, trata-se de uma idealidade, algo a ser constantemente buscado e construído como o próprio conceito de justiça ${ }^{44}$.

A construção do conceito de Sustentabilidade envolve, também, o futuro da humanidade no planeta, tendo em vista os níveis de degradação ambiental praticados.

\section{DO DESENVOLVIMENTO SUSTENTÁVEL COMO VIA PARA A SUSTENTABILIDADE MULTIDIMENSIONAL}

A concretização da Sustentabilidade em suas múltiplas dimensões significa a possibilidade de uma nova Sociedade. A atual crise ambiental exige mudanças de comportamento há muito arraigadas e determinam, na verdade, novos paradigmas a serem superados.

${ }^{42}$ SACHS, Ignacy. Desenvolvimento: includente, sustentável, sustentado. Rio de janeiro: Garamond, 2008. p. 15.

${ }^{43}$ FREITAS, Marcílio de; FREITAS, Marilene Corrêa da Silva. A sustentabilidade como paradigma: cultura, ciência e cidadania. Petrópolis, RJ: Vozes, 2016. p. 16.

${ }^{44}$ BODNAR, Zenildo; FREITAS, Vladimir Passos de; SILVA, Kaira Cristina. A epistemologia interdisciplinar da sustentabilidade: por uma ecologia integral para a sustentação da casa comum. Revista Brasileira de Direito, 12(2): 59-70, jul.-dez. 2016. p. 64. 
O capitalismo sustentável necessitará mais do que apenas tecnologia e mercados que promovam ativamente a desmaterialização. É necessário repensar os conceitos estabelecidos de igualdade social, justiça ambiental e ética empresarial. Contudo, o olhar multidimensional para o capital ampliará também para o capital humano, social e natural.

A Sustentabilidade é um projeto a ser alcançado pelo planeta e o Desenvolvimento Sustentável pode vir a ser o melhor caminho para tornar este projeto possível.

A necessária diferenciação entre os termos Sustentabilidade e Desenvolvimento Sustentável, conforme apresentado nos dois capítulos precedentes, permite entender o Desenvolvimento Sustentável como uma via para se alcançar a Sustentabilidade. Nesse sentido, para Ferrer, “o desenvolvimento sustentável não precisa ser contraditório à sustentabilidade, antes, pode ser mais um dos caminhos para alcançar uma sociedade sustentável" ${ }^{45}$.

Na mesma linha, Souza assinala que

As diferenças entre Sustentabilidade e Desenvolvimento Sustentável afloram com um processo em que a primeira se relaciona com o fim, enquanto o segundo com o meio. $\mathrm{O}$ Desenvolvimento Sustentável como meio para que seja possível obter equilíbrio entre o progresso, a industrialização, o consumo e a estabilidade ambiental, como objetivo a Sustentabilidade e o bem estar da sociedade ${ }^{46}$.

A sustentabilidade é parte de uma utopia, ou seja, compõe a visão de futuro sobre a qual a civilização contemporânea cria seus projetos e alicerça as suas esperanças. Segundo Matias, "a sustentabilidade seria, dessa forma, o quarto grande ideal da modernidade - ao lado da liberdade, igualdade e fraternidade -, surgido no fim do século XX" ${ }^{47}$.

A construção de um conceito necessariamente transdisciplinar de Sustentabilidade é um “objetivo complexo e sempre será uma obra em construção. Afinal, trata-se de uma idealidade, algo a ser constantemente buscado e construído como o próprio conceito de Justiça". ${ }^{48}$

${ }^{45}$ FERRER, Gabriel Real; GLASENAPP, Maikon Cristiano; CRUZ, Paulo Márcio. Sustentabilidade: um novo paradigma para o direito. Revista Novos Estudos Jurídicos - Eletrônica, Vol. 19 - n. 4 - Edição Especial 2014. p. 1455.

${ }^{46}$ SOUZA, Maria Claudia da Silva Antunes de Souza; MAFRA, Juliete Ruana Mafra. A sustentabilidade e seus reflexos dimensionais na avaliação ambiental estratégica: o ciclo do equilíbrio do bem estar. p. 4. Disponível em: <http://www.publicadireito.com.br/artigos/?cod=ec82bd533b0033cb >. Acesso em: 27 mai. 2017.

${ }^{47}$ MATIAS, Eduardo Felipe P. A humanidade contra as cordas: a luta da sociedade global pela sustentabilidade. São Paulo: Paz e Terra, 2014. p. 55.

48 CARNEIRO, Cheila da Silva dos Passos; STAFFEN, Márcio Ricardo. Da caracterização básica do direito ambiental ao paradigma da sustentabilidade: o contributo de Gabriel Real Ferrer. In: SOUZA, Maria Claudia da Silva Antunes de; GARCIA, Heloíse Siqueira. (Orgs). Lineamentos sobre Sustentabilidade segundo Gabriel Real Ferrer. Dados eletrônicos. Itajaí: UNIVALI, 2014. Disponível em: 〈http://www.univali.br/ppcj/ebook>. Acesso em: 25 mai. 2017. p. 218. 
Para Ferrer, o Direito Ambiental não tem sentido se não na sua acepção mundial, tendo em vista inclusive a questão de sua classificação como Direito Difuso. Os titulares da relação jurídica passam a ser todos aqueles afetados pela relação de fato, independentemente da conformação jurídica ${ }^{49}$.

Nesse sentido, entende-se a adesão integral dos Estados aos Objetivos de Desenvolvimento Sustentável como a alternativa que possibilita a concretização da Sustentabilidade em suas múltiplas dimensões.

Os Objetivos do Desenvolvimento Sustentável exemplificam o que Gonçalves chama de soft law do Direito Ambiental Internacional, ou seja, guias de conduta não obrigatórias adotadas em processos internacionais ${ }^{50}$. Orientarão o desenvolvimento para os próximos quinze anos, oferecendo uma oportunidade de atender aspirações globais dos cidadãos para um futuro mais pacífico, próspero e sustentável.

Ressalta-se a necessidade de envolvimento dos Estados tanto no âmbito interno, nacional, quanto no âmbito externo, internacional, Bosselmann defende a aplicação do princípio da Sustentabilidade enquanto princípio jurídico basilar da ordem jurídica local e internacional. Argumenta que contribui com a "ecologização" dos demais princípios e, desde que devidamente impulsionado pela força real da sociedade civil, servirá também como caminho para uma governança com sustentabilidade ecológica e social ${ }^{51}$.

A transformação da sociedade contemporânea em sociedade efetivamente sustentável passa, obrigatoriamente, pelo compromisso em cumprir com as metas dos Objetivos de Desenvolvimento Sustentável, garantido a capacidade de se perpetuar indefinidamente no tempo em condições que garantam a qualidade ambiental, justiça social e economia sustentável.

\section{CONSIDERAÇÕES FINAIS}

Em suma, o desenvolvimento sustentável vem provocando um repensar à ordem mundial estabelecida, à economia como é praticada atualmente, à noção de soberania, à educação e à forma como é transmitido o conhecimento e, ao modo de se fazer política.

${ }^{49}$ FERRER, Gabriel Real. La construcción del Derecho Ambiental. Revista Aranzadi de Derecho Ambiental (Pamplona, Espanã), n. 1, 2002, págs. 73-94.

50 GONÇALVES, Alcindo Fernandes; COSTA, José Augusto Fontoura. Governança Global e Regimes Internacionais. São Paulo: Almedina, 2011. p. 98.

${ }^{51}$ BOSSELMANN, Klaus. The principle of sustainability: transforming law and Governance. p. 79 e ss. 
Contudo, esta transição não ocorrerá de maneira espontânea, se faz necessário, um planejamento em longo prazo, com vontade de se estabelecerem objetivos sólidos e, então, ano após ano, se deslocar na direção de sua obtenção.

Ressalta-se, a sustentabilidade foi definida a partir de um longo processo histórico, bem como, a tomada de consciência sobre os problemas ambientais, crises econômicas e desigualdades sociais. Oferece uma grande esperança de amenizar os problemas entre nossa atividade econômica e a nossa atividade humana. Todavia, a ideia de sustentabilidade deverá permear concepções, planos, políticas e agendas de ação de uma nova ordem mundial, desde que o desenvolvimento sustentável seja efetivado na prática. O conceito de Desenvolvimento Sustentável mostrou-se incompleto, limitado e, do ponto de vista da preservação ambiental, absorveu as influências de uma visão reducionista.

Sabe-se que a transição para a sustentabilidade exigirá que se transfira a ênfase no crescimento econômico (com seu enfoque em quantidade) para o efetivo desenvolvimento sustentável (com seu enfoque na qualidade econômica, ambiental e social). Por sua vez, isso dependerá da nossa capacidade de pensar a um prazo mais longo de reconhecer que a qualidade dependerá da nossa capacidade de reconhecer, respeitar, administrar e sustentar a diversidade. É nesse sentido que os Objetivos de Desenvolvimento Sustentável configuram um importante passo para conciliar desenvolvimento e sustentabilidade.

\section{REFERÊNCIAS}

BODNAR, Zenildo; FREITAS, Vladimir Passos de; SILVA, Kaira Cristina. A epistemologia interdisciplinar da sustentabilidade: por uma ecologia integral para a sustentação da casa comum. Revista Brasileira de Direito, 12(2): 59-70, jul.-dez. 2016.

BOFF, Leonardo. Sustentabilidade: o que é, o que não é. Petrópolis, RJ: Vozes, 2015.

BOSSELMANN, Klaus. The principle of sustainability: transforming law and governance. Ashgate, Farnham, 2008.

CANOTILHO, José Joaquim Gomes. O Princípio da sustentabilidade como Princípio estruturante do Direito Constitucional. Revista de Estudos Politécnicos - Polytechnical Studies Review, 2010, Vol VIII, nº 13, 007-018.

CARNEIRO, Cheila da Silva dos Passos; STAFFEN, Márcio Ricardo. Da caracterização básica do direito ambiental ao paradigma da sustentabilidade: o contributo de Gabriel Real Ferrer. In: SOUZA, Maria Claudia da Silva Antunes de; GARCIA, Heloíse Siqueira. (Orgs). Lineamentos 
sobre Sustentabilidade segundo Gabriel Real Ferrer. Dados eletrônicos. Itajaí: UNIVALI, 2014. Disponível em: 〈http://www.univali.br/ppcj/ebook>. Acesso em: 25 mai. 2017.

CARVALHO, Isabel Cristina de Moura. Educação para sociedades sustentáveis e ambientalmente justas. REMEA Revista Eletrônica do Mestrado em Educação Ambiental. v. especial. Dez 2008. Rio Grande/RS. p. 46-55. Disponível em: <http://www.seer.furg.br/remea/article/view/3387/2033>. Acesso em: 02 ago. 2017.

DIEGUES, Antonio Carlos S. Desenvolvimento sustentável ou sociedades sustentáveis: da crítica dos modelos aos novos paradigmas. São Paulo em Perspectiva. São Paulo, v. 6, n. 1-2, p. 22-29, jan./jun. 1992.

DOVERS, S.R.; HANDMER, J.W. Uncertainty, sustainability and change. Global Environmental Change, v.2, n.4, p.262-276, 1992.

ELKINGTON, John. Canibais com garfo e faca. São Paulo: M. Books do Brasil Editora Ltda, 2012.

FERNANDES, Marcionila. Desenvolvimento sustentável: antinomias de um conceito. Raízes. v. 21. N.02. jul-dez/2002. Campina Grande. p. 246-260. Disponível em: <http://www.ufcg.edu.br/ raizes/artigos/Artigo_73.pdf>. Acesso em: 02 ago. 2017.

FERRER, Gabriel Real. La construcción del Derecho Ambiental. Revista Aranzadi de Derecho Ambiental (Pamplona, Espanã), n. 1, 2002, págs. 73-94.

FERRER, Gabriel Real; GLASENAPP, Maikon Cristiano; CRUZ, Paulo Márcio. Sustentabilidade: um novo paradigma para o direito. Revista Novos Estudos Jurídicos Eletrônica, Vol. 19 - n. 4 - Edição Especial 2014.

FREITAS, Juarez. Sustentabilidade: direito ao futuro. 2. ed. Belo Horizonte: Fórum, 2012.

FREITAS, M. A década de educação para o desenvolvimento sustentável - do que não deve ser ao que pode ser. In: Congresso Ibero-Americano de Educação Ambiental, 5, 2007, Joinville. Anais. Joinville: Associação Projeto Roda Viva, 2007.

FREITAS, Marcílio de; FREITAS, Marilene Corrêa da Silva. A sustentabilidade como paradigma: cultura, ciência e cidadania. Petrópolis, RJ: Vozes, 2016.

GONÇALVES, Alcindo Fernandes; COSTA, José Augusto Fontoura. Governança Global e Regimes Internacionais. São Paulo: Almedina, 2011.

LIMA, A. G. O debate da sustentabilidade na sociedade insustentável. 1997. Disponível em: <http://www.ufmt.br/gpea/pub/GuLima_sustentabilidade>. Acesso em: 11 abr. 2010.

MATIAS, Eduardo Felipe P. A humanidade contra as cordas: a luta da sociedade global pela sustentabilidade. São Paulo: Paz e Terra, 2014.

MILARÉ, Édis. Direito do Ambiente - doutrina - jurisprudência - glossário. 4. ed. rev., atual. E ampl. São Paulo: Editora Revista dos Tribunais, 2005.

MORIN, Edgar; KERN, Anne Brigitte. Terra-Pátria. Porto Alegre: Sulina, 1995. 
NOVAES, Washington. Agenda 21: um novo modelo de civilização. In: MELLO, Celso de Albuquerque (Coord.). Anuário: direito e globalização, 1: a soberania. Rio de Janeiro: Renovar, 1999.

PIERRI, Naína. Historia del concepto de desarrollo sustentable. In: FOLADORI, Guilhermo; PIERRI, Naína (Coords). ¿Sustentabilidad? Desacuerdos sobre el desarrollo sustentable. México, H. Cámara de Diputados, Universidad Autónoma de Zacatecas y Porrúa.

SACHS, Ignacy. Desenvolvimento: includente, sustentável, sustentado. Rio de janeiro: Garamond, 2008.

SOUZA, Maria Cláudia da Silva Antunes de; GARCIA, Rafaela Schmitt. Sustentabilidade e desenvolvimento sustentável: desdobramentos e desafios pós-relatório Brundtland. In: Sustentabilidade meio ambiente e sociedade [recurso eletrônico]: reflexões e perspectivas, volume II. SOUZA, Maria Cláudia da Silva Antunes de; ARMADA, Charles Alexandre. Florianópolis, SC: Empório do Direito, 2016.

SOUZA, Maria Cláudia da Silva Antunes de; MAFRA, Juliete Ruana Mafra. A sustentabilidade e seus reflexos dimensionais na avaliação ambiental estratégica: o ciclo do equilíbrio do bem estar. p. 4. Disponível em: <http://www.publicadireito.com.br/artigos/?cod=ec82bd533b0033cb>. Acesso em: 27 mai. 2017.

TOYNBEE, Arnold. A humanidade e a mãe-terra: uma história narrativa do mundo. Rio de janeiro: Guanabara, 1987.

UNITED NATIONS. Declaration on the Right to Development. Disponível em: <http://www.un.org/documents/ga/res/41/a41r128.htm>. Acesso em: 06 ago. 2017.

UNITED NATIONS. Our Common Future. Disponível em: <http://www.undocuments.net/our-common-future.pdf>. Acesso em: 28 jul. 2017.

VEIGA, José Eli da. A desgovernança mundial da sustentabilidade. São Paulo: Editora 34, 2013.

VIZEU, Fabio; MENEGHETTI, Francis Kanashiro; SEIFERT, Rene Eugenio. Por uma crítica ao conceito de desenvolvimento sustentável. 3Cad. EBAPE.BR, v. 10, nº 3, artigo 6, Rio de Janeiro, Set. 2012. 